\title{
A DEFENSE OF MORAL PERCEPTION
}

\author{
Justin McBrayer \\ Dr. Peter J. Markie, Dissertation Supervisor
}

\begin{abstract}
I defend the possibility of moral perception and the contentious view that at least some of our moral knowledge is perceptual knowledge. The first part of the dissertation is spent establishing the possibility of moral perception by showing that putative cases of moral perception meet both the internal and external constraints on perception. For example, I argue that it is possible for a subject to have a mental state that represents a moral property and that we can be in the appropriate causal relation with moral facts regardless of whether they turn out to be secondary natural properties, non-secondary natural properties, or non-natural properties. The second part of the dissertation is spent showing that moral perception has epistemic import. I show that moral perception is sufficient for moral knowledge on a number of contemporary accounts of the epistemology of perception, including indirect realist, direct realist, evidentialist, and proper functionalist accounts of perceptual knowledge.
\end{abstract}

